\title{
Política, violencia y literatura ${ }^{1}$
}

\author{
Karl Kohut
}

Katholische Universität Eichstätt

Tomando como punto de partida la opinión general de que América Latina es el continente violento por excelencia y la hipótesis defendida por Ariel Dorfman (1972) se analiza aquí la cuestión de la violencia política, ciñéndose a la literatura de la segunda mitad del siglo XX. Tras discutir las definiciones (divergentes) de la violencia propuestas por la filosofía política, se pasa a una fenomenología de la violencia en la literatura, examinando hasta qué punto y en qué sentido ésta sería el carácter distintivo de la literatura latinoamericana. Finalmente, se analiza la metarreflexión sobre la violencia política en la literatura ficcional, centrándose en tres puntos: (1) el (presunto) ser violento del mundo latinoamericano, (2) la violencia estatal, y (3) la violencia de la resistencia. Se constata, entre otras cosas, que ha habido una tendencia a atacar la violencia estatal y defender la de la resistencia; tendencia comprensible en tiempos de dictadura, pero que se vuelve problemática bajo una democracia. Dos preguntas cierran este trabajo: hasta qué punto la violencia es un fenómeno de la cultura, que crece en su mismo seno, y no un fenómeno extracultural dirigido contra ella, y hasta dónde la libertad individual y la seguridad cívica pueden ser conciliadas, punto que ha ocupado un lugar central en la discusión internacional después de los acontecimientos del 11 de septiembre.

En América la violencia es la prueba de que yo existo

ARIEL DORFMAN: Imaginación y violencia en América

La Europa que nos juzga, que nos mira desdeñosa, es la mayor suma de genocidios de la historia de la humanidad, es el imperio de la violencia y el racismo

MEMPo GIARDINELLI: Qué solos se quedan los muertos

Que América Latina es el continente violento por excelencia parece opinión común, a pesar de que los acontecimientos recientes (sobre todo los del 11 de septiembre 2001) y no tan recientes ocurridos en distintos países parecerían indicar que no se encuentra solo en este sentido. La última década, durante la cual se ha completado la transición democrática en una serie de países que habían sufrido dictaduras militares, no ha logrado borrar los dolorosos recuerdos que pueden volver a la superficie en cual-

1 El presente artículo se basa en una conferencia dada en el Congreso Anual de la Asociación Alemana de Investigación sobre América Latina (ADLAF), celebrado en Hamburgo en 1999 y dedicado a la violencia en América Latina. 
quier momento, tal como ocurre cuando otro oficial argentino culpable de torturas es desenmascarado o, en el caso de Chile, con el juicio de Pinochet. Según una estadística de los secuestros a nivel mundial establecida en el 2000 para la compañía de seguros inglesa Hiscox Group y publicada en un resumen por Newsweek en julio de ese mismo año, entre los diez países con el mayor número de secuestros en 1999 (y que representan el $92 \%$ del problema a escala mundial), figuran cinco latinoamericanos. No sorprenderá mucho que Colombia se encuentre en primer lugar con un total de 972 secuestros - "uno de los países más inseguros y subvertidos del mundo", según palabras de Gabriel García Márquez. ${ }^{2}$ "Eramos, y de lejos, el país más criminal de la tierra", dice el narrador de la novela La Virgen de los Sicarios, de Fernando Vallejo. ${ }^{3}$ A pesar de las profundas diferencias que existen entre ellos, las revueltas en Chiapas, la acción de la guerrilla y la mafia en Colombia, los excesos de la policía, los altos índices de criminalidad (para indicar sólo unos pocos fenómenos), colaboran a mantener viva la fama de violento de la que sufre el subcontinente latinoamericano.

La violencia real del subcontinente tiene su contraparte en la literatura. Así lo expresa Ariel Dorfman en su ensayo "La violencia en la novela hispanoamericana actual":

Decir que la violencia es el problema fundamental de América y del mundo es sólo constatar un hecho. Que la novela hispanoamericana refleja esa preocupación se advierte en cada página escrita en nuestro continente, esas páginas que son como la piel de nuestros pueblos, los testigos de una condición siempre presente.

Dorfman recogió este ensayo en 1970 en un volumen que lleva el título emblemático de Imaginación y violencia en América. ${ }^{4} \mathrm{Si}$ aceptamos su tesis de la omnipresencia de la violencia en la narrativa hispanoamericana como hipótesis de trabajo, escribir sobre la violencia en la literatura

2 García Márquez, Gabriel: Noticia de un secuestro. Barcelona, 1996, pág. 83.

3 Vallejo, Fernando: La Virgen de los Sicarios. Santafé de Bogotá,1998 [1994], pág. 10.

4 "La violencia en la novela hispanoamericana actual". En Dorfman, Ariel: Imaginación y violencia en América. 2. a ed. Barcelona, 1972 [1970], págs. 9-37 (La cita en pág. 9). A pesar de que han pasado treinta años desde su primera edición, el ensayo de Dorfman sigue siendo considerado como una reflexión paradigmática sobre la problemática; de ello es prueba su inclusión en la colección de los ensayos más significativos sobre la literatura latinoamericana en Sosnowski, Saúl (ed.): Lectura crítica de la literatura americana. Actualidades fundacionales, Colección Ayacucho, Caracas, 1997, págs. 387-410. Aunque difiero de este ensayo en más de una oportunidad, el peso que parecen tener sus argumentos me ha motivado a utilizarlo como hilo conductor en este trabajo. 
latinoamericana significaría escribir sobre esta literatura en su totalidad, incluyendo al Brasil y tomando en cuenta todos los géneros literarios. Ante la clara necesidad de restringir el campo de observación, opto por la violencia política, dejando de lado la violencia en el nivel privado. Sin embargo, esta opción no niega la interrelación entre ambas, lo que discutiré más adelante.

\section{Reflexiones teóricas}

Todos sabemos (o creemos saber) lo que es la violencia. Sin embargo, si comparamos las definiciones dadas en las obras de referencia, nos damos cuenta de que existe una gran variedad e, incluso, ciertas contradicciones. Peter Waldmann, en su artículo sobre la violencia política, distingue entre violencia personal, institucional y estructural. La violencia personal es definida como "una interacción social que se caracteriza por la imposición de pretensiones y esperanzas o, más simplemente, por el enfrentamiento corporal directo". La violencia institucional, por su parte, es "el poder de mandar sobre otras personas, apoyado en sanciones físicas, que se concede a personas que ocupan ciertas posiciones". Finalmente, su concepción de la violencia estructural, inspirada en la del investigador noruego Galtung, la define como "la causa de la diferencia entre la realización somática y espiritual del hombre y su realización potencial". ${ }^{5}$ La violencia estructural no se puede imputar a una persona o institución determinada, sino - de una manera algo vaga - a las circunstancias reinantes que impiden, por ejemplo, que un enfermo pobre reciba el tratamiento médico adecuado. Este ejemplo hace ver que la violencia estructural pertenece, en última instancia, al campo de la violencia institucional, porque es la consecuencia de una situación política en el sentido más amplio. ${ }^{6}$ El concepto de violencia estructural es, además, un fuerte indicio de la evolución que ha sufrido el concepto de violencia en general, dado que dudo de que las situaciones que abarca hubieran sido consideradas como violentas en tiempos anteriores.

5 Waldmann, Peter: "Politische Gewalt“. En: Pipers Wörterbuch zur Politik, I, 1985, págs. 741-745 (la cita en pág. 742). Las traducciones del alemán y del francés en este ensayo son mías.

6 Scruton, por el contrario, considera el concepto de violencia estructural como mera coartada, por parte de pensadores radicales, para poder justificar mejor la oposición violenta. Scruton, Roger: A Dictionary of Political Thought. London and Basingstoke, 1982, pág. 486. 
Más concreta es la definición que encontramos en The Blackwell Encyclopaedia of Political Thought:

In its most basic sense, violence means inflicting damage on people, by killing, maiming or hurting them. Its meaning may be extended to cover the threat of such damage, and to psychological as well as physical harm. Violence may also be defined so as to include destruction of property. Some political writers have stretched the concept of violence to embrace oppressive political, social, or economic systems that damage people living under them.?

El autor de esta entrada no distingue entre violencia personal e institucional, pero sí diferencia la violencia estructural, a la cual se alude claramente en la última frase de la cita. A continuación, distingue entre formas instrumentales y expresivas de la violencia, siendo la instrumental una violencia utilizada racionalmente para alcanzar ciertos objetivos, mientras que la expresiva, sea individual o colectiva, es un objetivo en sí misma.

La amenaza de la violencia y el acto de violencia contra la propiedad que aparecen, en la definición, como una extensión posible del concepto de violencia, son, en realidad, centrales para la eficacia de la violencia en tanto que instrumento político. Esto se debe a que la violencia real se dirige siempre contra un número específico de personas; de modo general, contra aquellos que el régimen imperante considera más peligrosos. Lo que toca a todos los ciudadanos es la amenaza de la violencia (tanto contra la persona como contra la propiedad), y es esta amenaza la que les produce miedo y los induce a la obediencia cívica. Como lo mostraré posteriormente, este aspecto juega un papel vital en la expresión literaria de la violencia.

Es sólo de paso que puedo mencionar las distintas teorías sobre el origen de la violencia, teorías que ocupan un puesto importante en la filosofía política: según éstas, la violencia radica en la propiedad privada (Marx y muchos otros), o en la carencia de los medios para (sobre)vivir (Sartre), o en la rebelión contra Dios (la teología cristiana).

Las teorías de índole política tienen en común el relacionar el problema de la violencia con la sociedad. Según el artículo "violencia" del Dictionnaire des littératures, la violencia "es literalmente el contenido de las sociedades, no lo que reprimen, sino lo que organizan, el horizonte de enfrentamiento que sitúa el diálogo". ${ }^{8}$ Aun más lejos va Wolfgang Solfsky

7 "Violence", en The Blackwell Encyclopaedia of Political Thought. Oxford, 1987, pág. 540s.

8 "Violence", en Demoignon, Jacques (ed.): Dictionnaire des littératures, París, 1986. 
en su reciente Tratado sobre la violencia (Traktat über die Gewalt, 1996) en el cual pone en relación violencia y cultura: la violencia no es, según él, un fenómeno antagónico a la cultura, sino un producto de ella:

La violencia es ella misma un producto de la cultura humana, un resultado del experimento de la cultura. Se la aplica en el nivel respectivo de las fuerzas destructivas. Puede hablar de retroceso sólo aquél que cree en progresos. Empero, desde siempre los hombres destruyen y asesinan con gusto y, por así decirlo, como naturalmente. Su cultura les habilita a dar forma y contorno a esta potencialidad. El problema no reside en la escisión entre las fuerzas oscuras del instinto y las promesas de la cultura, sino en la correspondencia entre violencia y cultura. La cultura no es, en modo alguno, pacifista. Ella forma parte del desastre. ${ }^{9}$

Aplicando esta misma idea a la realidad latinoamericana, el colombiano Rafael Humberto Moreno Durán escribe que "la 'barbarie' de la dictadura sólo es posible con los medios que le ofrece la 'civilización' asentada en la ciudad que crece". ${ }^{10}$

Tanto en la teoría como en la práctica política, el problema de la violencia está ligado al del poder, hasta tal punto que es imposible hablar de poder sin incluir la violencia, y hablar de ésta implica a aquél. ${ }^{11}$ Desde una perspectiva filosófica, Schwartländer insiste en que hay que distinguir entre los dos conceptos, que a menudo son considerados idénticos. En el sentido más amplio, el poder se funda en su capacidad de imponer la voluntad del que lo ejerce. En este sentido - escribe- este ejercicio del poder es neutral. Sin embargo, se convierte en violencia si es impuesto contra la voluntad de otro(s) hombre(s). La violencia convierte al otro en una cosa a disposición del poderoso; en este sentido, la violencia es profundamente inhumana. Sin embargo, Schwartländer admite que también existe una forma de violencia que puede considerarse como justificada, lo que vale sobre todo para situaciones de legítima defensa. ${ }^{12}$

Desde una perspectiva politológica, Scruton describe la interrelación entre los dos conceptos definiendo el poder como "the ability to achieve whatever effect is desired, whether or not in the face of opposition. Power

9 Solfsky, Wolfgang: Traktat über die Gewalt. Frankfurt a.M., 1996, pág. 226.

10 Moreno Durán, Rafael Humberto: De la barbarie a la imaginación. La experiencia leída. 2. ${ }^{\text {a }}$ ed. corregida y aumentada. Bogotá, 1988, pág. 407.

11 En este sentido, este ensayo constituye un correlato del que publiqué sobre el poder en 1995. Kohut, Karl: "El poder como tema literario“. En: Christian De Paepe, Nadia Lie, Luz Rodríguez Carranza y Rosa Sanz Hemida (eds.): Literatura y poder. Leuven, 1995, págs. 59-91.

12 Schwartländer, Johannes: "Macht", en Hg. von H. Krings, H. M. Baumgartner und C. Wild. München: Handbuch philosophischer Grundbegriffe, 1973, III, págs. 868-877, págs. 868-870. 
[...] may be based in consent or in coercion". ${ }^{13}$ Waldmann habla de "teoría de la coerción" (Zwangstheorie) y "modelos de consenso". ${ }^{14}$ El concepto central de la definición de Scruton es, en lo que toca a nuestro contexto, "coerción". Paso por alto el de "consenso" en tanto que no implica violencia, al menos en teoría. El concepto de "coerción", por el contrario, nos lleva directamente a la problemática de la violencia política. Empero, ¿cómo distinguir "coerción" de "violencia"? Siempre siguiendo a Scruton, coerción sería

any force or threat of force which reduces the freedom of an action, so that, in performing it, an agent acts less freely than he might have done, although not unintentionally. ${ }^{15}$

En esta definición, la significación de "coerción" está muy cerca de la de "violencia", sobre todo la "physical coercion" que distingue de la "moral coercion". ${ }^{16}$ En otro lugar, por el contrario, distingue coerción de violencia precisamente por la ausencia de fuerza física. ${ }^{17} \mathrm{~A}$ pesar de estas imprecisiones y hasta contradicciones, el concepto de coerción me parece útil para describir la acción legal de un gobierno legal — basado en el consenso de los ciudadanos - para realizar los objetivos gubernamentales y mantener la paz cívica. Esto puede significar que el gobierno tenga que usar la coerción para imponer sus objetivos contra los que rompan esta paz o amenacen con hacerlo, sea a nivel individual (criminalidad) o de grupo (mafia o resistencia armada contra una democracia). "Violencia", por el contrario, sería el abuso del poder en una democracia (por ejemplo, a través de la violencia policial) o, en una dictadura, la suma de las acciones del gobierno para mantener la paz social y, con ello, mantenerse en el poder.

Es cierto que esta diferenciación entre coerción y violencia puede parecer ociosa, tanto desde la perspectiva de los gobernantes como de quienes se resisten a aceptar su autoridad, si bien por causas opuestas. Los regímenes autoritarios nunca tuvieron escrúpulos en recurrir a la violencia cuando les parecía necesario, y en cuanto a quienes se niegan a aceptar la autoridad de un gobierno, sea legítimo o ilegítimo, las acciones del estado siempre habrán de parecerles opresivas, y su resistencia, por ende, justifi-

13 Scruton: A Dictionary of Political..., pág. 366.

14 Waldmann: "Politische Gewalt"..., pág. 742.

15 Scruton: A Dictionary of Political..., pág. 70.

16 Ibídem.

17 Ibídem, pág. 486. 
cada. En ambos casos, la distinción entre coerción y violencia pierde toda importancia. En cuanto a la legitimación teórica de su actuación, los unos se referirán a Maquiavelo, y los otros, a Georges Sorel.

Estas reflexiones nos hacen ver que la distinción entre coerción y violencia nos lleva a un campo sumamente resbaladizo, lo que se debe, aparte de la dificultad inherente a la problemática, al hecho de que hacen falta, según Waldmann, "investigaciones sistemáticas sobre los mecanismos de la acción violenta del estado en situación de rutina". ${ }^{18} \mathrm{La}$ ausencia de una distinción clara, en la teoría política, entre violencia y coerción es tanto más deplorable cuanto que esta distinción es de importancia vital, tanto para la realidad política latinoamericana como para su literatura. La confusión entre ambos conceptos está en la base del escepticismo hacia el estado que comparten la mayoría de los intelectuales latinoamericanos.

Particularmente difícil es el problema de la defensa contra la violencia que se presenta en todos los niveles. Schwartländer (cf. más arriba) había señalado la situación de "legítima defensa". El caso más sencillo es tal vez el de la vida privada: hay un consenso en el derecho que tiene el individuo de defenderse, incluso violentamente, contra una agresión; derecho que se extiende hasta permitir la muerte del agresor. Los modos y los grados de defensa personal tolerados, sin embargo, varían mucho de una sociedad a otra. Mientras que, en los EE.UU., es considerado absolutamente normal la tenencia personal de armas de fuego, esto constituye una excepción en los países de la Unión Europea. Transferido al campo político, el problema se complica. Dejando de lado la cuestión de la resistencia pacífica, ¿a qué grado de abuso de poder y de violencia tiene que llegar un gobierno para que la resistencia armada se considere justificada? Es paradigmático el caso de la resistencia alemana contra Hitler. Incluso en este caso extremo, los conjurados tuvieron que pasar por encima de una serie de escrúpulos morales para decidir llevar a cabo el proyecto de matar al tirano. Finalmente, el problema aparece en las relaciones interestatales: el problema de la "guerra justa" tiene una larga tradición en el pensamiento político.

Si bien las distinciones y definiciones que he presentado son causa de controversia dentro de la reflexión teórica, lo son mucho más en la realidad política. Vuelvo a la distinción entre "coerción" y "violencia". Un criterio fundamental para la misma es —como señalé antes siguiendo a Schwartländer - la noción de derecho. Arrestar a un criminal en una demo-

18 Waldmann: "Politische Gewalt"..., pág. 744. 
cracia es percibido como un acto lícito de coerción, mientras que todo arresto en una dictadura (salvo el de un criminal obvio) es percibido como un acto violento. Este ejemplo es instructivo en varios sentidos. Primero, sabemos que el concepto de derecho está sujeto a interpretaciones ideológicas. Segundo, que la violencia está sujeta a la percepción del que la ejerce, del que la sufre, o de un tercero no involucrado directamente que la observa, o que, al tener conocimiento de ella, la juzga. Para complicar las cosas, el concepto de violencia (y de su uso legal, semilegal o ilegal) es distinto en diferentes culturas, y ha estado, además, sujeto a profundos cambios históricos. Hasta tiempos bastante recientes, por ejemplo, la tortura era considerada un instrumento legal de la justicia. Otro ejemplo es el caso límite de la pena máxima y su implementación. En cuanto a los modos de ejecución del condenado, muchos de los que se utilizaron en Occidente (sin hablar de otras culturas) hoy nos parecen bárbaros. La discusión se prolonga actualmente en y con respecto a los EE.UU., tanto en lo que hace a la legalidad de la ejecución como a la "humanidad" de los métodos utilizados en la misma. La violencia, en otras palabras, es un hecho sujeto a la percepción no sólo ideológica sino cultural e histórica que a su vez depende de una serie de factores. Esto vale sobre todo para situaciones políticas turbias en las cuales es difícil distinguir de qué lado está el derecho, y si las medidas empleadas son adecuadas o violentas. Finalmente, la denuncia de la violencia puede constituir un arma poderosa en el campo de la opinión pública, tanto por el lado gubernamental (contra guerrilleros, etc.) como por el lado resistente (contra el gobierno, la policía, etc.).

Las reflexiones anteriores se basan tácitamente en la suposición de que la distinción entre violencia política y la privada es evidente. Sin embargo, esta distinción es valedera sólo con ciertos matices. Dorfman ${ }^{19}$ define la violencia política como vertical y social, mientras que la privada sería horizontal e individual. En la violencia vertical, podemos distinguir entre la de "arriba" — es decir, de la parte del poder-y la de "abajo", es decir de la parte del pueblo. ${ }^{20}$ Se comprende que la violencia desde arriba se identifica con dictadura y opresión, mientras que la de abajo con resistencia y libertad.

En este ensayo, acepto la diferenciación entre violencia vertical y horizontal porque permite delimitar los campos de observación. Cabe, sin embargo, señalar que los límites no son tan nítidos como lo sugiere la defi-

19 Dorfman: "La violencia en...", págs. 18s.

20 Waldmann: "Politische Gewalt"..., pág. 744. 
nición. La violencia de los narcotraficantes pertenece tanto a la esfera privada como a la política. Discutiré este punto más adelante a propósito del reportaje de García Márquez sobre los secuestros en Colombia a principios de los años noventa. Más aún, la violencia privada puede convertirse en problema político si pasa de ser un fenómeno aislado a uno común. Si la criminalidad civil, por ejemplo, aumenta tanto que es sentida como insoportable por parte de la población, la violencia que, según la definición, es privada, se convierte en un problema político.

Esta problemática ya lo suficientemente intrincada se complica más si la transferimos a la literatura. La obra literaria es la expresión de una perspectiva que difiere según los géneros literarios. En un ensayo, una opinión expuesta es la expresión directa de la opinión del autor. En la novela, por el contrario, una opinión expuesta por los personages o incluso por el narrador sólo raras veces puede relacionarse directamente con el autor. En la mayoría de los casos sólo puede hacerse indirectamente, a través del narrador implícito. El autor dispone de una amplia gama de recursos para expresar su visión y dirigir la simpatía o antipatía del lector, lo que le permite, como advierte Sábato en Abaddón, mostrar las diferentes caras de un problema.

Ahora bien, es una convicción común que la literatura es, en su esencia, humana y que, por ende, debe contribuir a la humanización del mundo (a pesar de que esto último no ha gozado siempre de consenso entre los literatos). En este sentido, podemos esperar de ella que denuncie la violencia en todas sus formas. La literatura latinoamericana cumple, en su conjunto (y con muy pocas excepciones), con estas expectativas. Sin embargo, cabe tener en cuenta que el compromiso del escritor con la libertad lo puede llevar, aunque sea inconscientemente, a acentuar la violencia del lado opuesto y a minimizar (o justificar) la violencia del lado propio.

Hay que contar, además, con las diferentes tendencias, formas y corrientes literarias en boga durante el siglo pasado, las cuales inevitablemente influyeron en los diferentes modos de enfocar y presentar la violencia. Finalmente, cabe señalar que la sensibilidad social y literaria hacia la violencia pueden estar en correspondencia o diferir según las circunstancias. En tiempos de dictadura, pudimos observar una alta correspondencia entre ambas. En la actualidad, por el contrario, se han separado hasta presentarse como opuestas. Volveré sobre estos puntos al final de este ensayo.

Con estas reflexiones no deseo abogar por un relativismo absoluto. La violencia sigue siendo violencia; empero hay que tener en cuenta que la realidad política puede ser muy ambigua, y más aun su expresión literaria. 


\title{
La literatura latinoamericana: ¿una literatura de la violencia?
}

En su ensayo citado al comienzo de este trabajo, Dorfman propone una doble tesis: 1) América Latina es, en su esencia, violenta; 2) la literatura hispanoamericana es más violenta que la de otras regiones. Puesto que la violencia real en las sociedades latinoamericanas no es el tema de este ensayo, no voy a discutir la tesis de si la sociedad latinoamericana es particularmente violenta o no en comparación con la de otros continentes. ${ }^{21}$ Más aun, y sobre todo en el caso de un investigador alemán, me parece indispensable cierta discreción al escribir sobre el tema de la violencia en otro continente, en vista de nuestra propia historia del siglo XX. Me parece, sin embargo, imprescindible, en el contexto de este ensayo, analizar la reflexión que hacen los escritores mismos sobre la violencia en sus obras, la cual abordaré en la tercera parte.

En cuanto a la segunda tesis, Dorfman la desarrolla a través de aseveraciones en extremo tajantes. "A partir del naturalismo — escribe- el problema de la violencia pasa a ser el eje de nuestra narrativa", ${ }^{22}$ constatación en la que se explaya unas páginas más adelante:

\begin{abstract}
Pocos son los personajes que pueden prescindir de la violencia en nuestra novelística. En la literatura europea, en cambio, y en muchas narraciones norteamericanas de los últimos veinte años [...], la mayor parte de los protagonistas termina por desentenderse de la violencia como solución, razonando que la dignidad consiste, justamente, en marginarse de la lucha en un mundo sucio, replegándose hacia refugios interiores y problemas interpersonales. Creen que pueden no tomar en cuenta a la violencia. ${ }^{23}$
\end{abstract}

Sin embargo, el corpus que elige Dorfman y la comparación que hace entre la producción novelesca latinoamericana de las décadas anteriores a 1970 con la europea y norteamericana de esa misma época es demasiado limitado para permitirle llegar a conclusiones tan tajantes. Si extendemos

21 Para el problema de la violencia en el pasado del subcontinente, tanto en la realidad histórica como en su representación literaria, ver los siguientes volúmenes colectivos: Duviols, Jean-Paul y Annie Molinié-Bertrand (eds.): La violence en Espagne et en Amérique (XVe-XIXe siècles). Actes du colloque international "Les raisons des plus forts". París, 1997. McFarlane, Anthony y Marianne Wiesenbron (coords.): Violencia Social y Conflicto Civil: América Latina, siglos XVIII-XIX, en Cuadernos de Historia Latinoamericana, n. ${ }^{\circ}$ 6, 1998. Para la violencia desde abajo, ver la obra enciclopédica de Balencie, Jean-Marc y Arnauld de La Grange: Mondes rebelles. Réédition revue et augmentée. París, 1999.

22 Dorfman: "La violencia en...", pág. 10

23 Ibídem, pág.15. 
el campo de observación históricamente, nos damos cuenta de que la violencia es omnipresente desde los comienzos, incluyendo la Biblia. Y no puede ser de otro modo puesto que la literatura revive conflictos que se resuelven, de preferencia, de modo violento. ¿Cuántos crímenes y muertos hay en la Ilíada, la Odisea, el teatro griego? ¿Cuántos en las tragedias de Shakespeare? Si esto es particularmente válido para la tragedia, donde los conflictos (y su solución violenta) constituyen la base misma de la trama, es igualmente cierto para la narrativa, si bien de manera diferente. A pesar de que la presencia de la violencia, el grado de la misma, su expresión directa o velada varían según las épocas, es difícil, si no imposible, encontrar una época en la cual esté ausente. "La violencia, incluso el horror, no han dejado nunca de estar en el corazón mismo del arte", escribe el novelista francés Marc Petit. ${ }^{24}$ La violencia es una constante de la literatura.

La tesis de Dorfman que sostiene que la narrativa hispanoamericana es particularmente violenta, debe ser discutida sobre este trasfondo. El problema es sumamente intrincado y exigiría un rastreo sistemático en un corpus extenso de obras, misión imposible en el marco de un breve ensayo. Por ende, los análisis que presento en este capítulo no pueden tener sino valor de ejemplo. Dicho esto, deseo proponer una doble hipótesis: (1) si bien la presencia de la violencia como elemento definidor de la literatura latinoamericana del siglo XX tiene sus raíces, sin duda alguna, en la realidad política e histórica del subcontinente, es decisiva la sensibilidad particular de los escritores e intelectuales ante ella; (2) por lo menos en la literatura del Boom y Posboom, el tema de la violencia se diversifica y cambia, según los distintos países y según la época, tanto en la fuerza de su presencia como en su representación literaria.

Una prueba provisional de la primera hipótesis es el hecho de que la gran mayoría (si no todos) de los fenómenos políticos violentos del siglo XX tiene su contraparte en la literatura. Entre ellos, podemos enumerar: la novela de la revolución mexicana, de la dictadura, de la guerrilla, de la violencia (en Colombia y Venezuela), la indigenista, la reacción literaria a erupciones violentas tales como la noche de Tlatelolco. Por otra parte, los períodos violentos del pasado ingresaron en el panorama literario con la novela histórica, sobre todo con la llamada nueva novela histórica de los últimos lustros, si bien es cierto que no faltan antecedentes de las mismas en las décadas anteriores. En todos los casos mencionados más arriba se

24 Petit, Marc: Eloge de la fiction. París, 1999, pág. 96. 
trata de ciclos con un número nutrido de obras que forman un corpus propio. Lo dicho respecto de la novela puede extenderse al teatro y a la poesía, puesto que muchos de esos ciclos incluyen igualmente piezas teatrales $\mathrm{y}$, por lo menos parcialmente, obras poéticas. ${ }^{25}$

Sin embargo, esta enumeración de los distintos ciclos de la violencia (seguramente incompleta) esconde un aspecto central: se trata de ciclos relacionados con determinados hechos políticos reales y que están, por ende, ceñidos a un tiempo y un espacio en particular. Así, en los años de mayor violencia de la Revolución Mexicana, la Argentina vivía un período de paz cívica. Décadas después, cuando los países del Cono Sur sufrían las dictaduras militares de los setenta y principios de los ochenta, la violencia política tenía mucho menos importancia en México. El Perú del Sendero Luminoso, la Colombia de los carteles de Medellín y de Cali son otros tantos casos de violencia limitados a una época y una zona en particular.

Si hacemos una contraprueba centrándonos esta vez en la obra de los autores más importantes, llegamos a una conclusión similar. La violencia ocupa, en efecto, un lugar importante en la obra de Rulfo, Sábato, Vargas Llosa, García Márquez, Fuentes o Cortázar — para tomar como ejemplo algunos autores ya canonizados de la segunda mitad del siglo XX. Lo mismo vale para los autores más jóvenes del llamado Posboom: Mempo Giardinelli, el autor cuya obra es, tal vez, la más marcada por la violencia, y Luisa Valenzuela en Argentina, Luis Britto García en Venezuela, José Emilio Pacheco en México, entre muchos otros más. Sin embargo, este mismo chequeo nos permite observar que en la producción de los autores mencionados hay obras que difícilmente podrían clasificarse bajo el signo de la violencia, sin hablar de la obra de otros autores de importancia como, por ejemplo, Alfredo Bryce Echenique. Un caso particularmente significativo es la obra de Borges. A pesar de que la violencia está presente en muchos de sus cuentos, sería difícil — si no absurdo - clasificarla bajo su signo. Es cierto que esta valoración es discutible y depende mucho de las diferentes concepciones de la violencia ya mencionadas. Además, no se puede llegar a una conclusión definitiva hasta haber realizado un análisis sistemático de la producción literaria de las últimas décadas.

Las reflexiones anteriores, empero, incluso sin este estudio sistemático, nos llevan a concluir en favor de las dos hipótesis que he propuesto. La mayoría de los autores latinoamericanos ha retomado, en sus obras, aspec-

25 La bibliografía sobre los diferentes ciclos es inmensa, lo que impide su inclusión en la de este ensayo. 
tos de la violencia real de sus países, lo que atestigua su sensibilidad hacia los problemas de sus pueblos. Sin embargo, la violencia no está presente, con una fuerza y un peso iguales, ni en la realidad política ni en las obras literarias de todo el subcontinente, sino que varía según los países y según las épocas. Prefiero, por ende, hablar de la violencia en la novela de la Revolución Mexicana, o en la novela dictatorial en vez de hablar de modo general de la literatura latinoamericana.

La generalización que conlleva la tesis de Dorfman se explica, tal vez, por el momento histórico en el que fue elaborada. Los años que van de los ' 60 a mediados de los ' 80 constituyen una etapa particularmente violenta de la historia del continente, y si bien — como ya he señalado - esto no es cierto para todos los países o para todo el período, fue sentida como tal por los intelectuales latinoamericanos. Un indicio de la certeza de esta hipótesis es el hecho de que fue en estos años cuando aparecieron las grandes novelas dictatoriales de Vargas Llosa, García Márquez, Carpentier, Roa Bastos y Uslar Pietri. Es sólo ahora, desde una cierta distancia, cuando podemos distinguir los diferentes matices en una imagen que en ese entonces debió parecer de un negro uniforme.

Volviendo, pues, a los distintos ciclos, podemos decir que tienen en común la tematización de la violencia en sus formas históricas particulares, pero que se distinguen en cuanto a su representación. Hasta mediados del siglo XX prevaleció la denuncia explícita de la violencia, bajo los cánones del naturalismo, de los distintos realismos o de la literatura comprometida a lo Sartre. Con el Boom, se impusieron formas más sofisticadas de representación de la violencia, sin que por ello perdiera fuerza la condena de la misma, tal como lo atestiguan las novelas dictatoriales mencionadas arriba. Un ejemplo particularmente instructivo lo constituyen las obras que surgieron de los sucesos de la noche de Tlatelolco, y cuyo abanico literario va desde el testimonio de La noche de Tlatelolco, de Elena Poniatowska, hasta la carnavalización en Palinuro de México, de Fernando del Paso, sin que falte la reflexión político-filosófica que encontramos en los ensayos de Octavio Paz. Los autores contemporáneos a las dictaduras militares del Cono Sur prefirieron formas alegóricas bajo un realismo aparente, siendo tal vez los ejemplos más conocidos Casa de campo, de José Donoso, e Incidente em Antares, de Erico Veríssimo. Sobre todo en la Argentina, son numerosas las novelas y piezas de teatro que reflejan la última dictadura militar a través de tramas alegóricas. La llamada novela negra alcanzó particular importancia en este contexto. 
De modo general, se puede decir que el tema de la violencia se plasma, en la literatura, en el choque entre los órganos de poder y el ciudadano. De ahí la aparición recurrente de la tortura como expresión máxima de la violencia, tortura que muchas veces termina con la muerte del torturado o con la destrucción de su personalidad. La literatura latinoamericana ofrece escenas de pesadilla que se incrustan en la memoria. La tortura, empero, no tiene que ser necesariamente física, existiendo métodos más sutiles, psíquicos, que pueden ser más eficientes que la violencia física. Así, por ejemplo, el trágico fin de Cara de Angel en la cárcel del Señor Presidente. Cuando los torturados son mujeres, la quiebra de su personalidad puede llevar a la víctima a enamorarse de su torturador, "verdadero tabú social", como escribe Estela Patricia Scipioni ${ }^{26}$ a propósito de Paso de dos (1990), de Eduardo Pavlovsky, uno de los autores que más se ha ocupado de la figura del torturador. El cuento "Cambio de armas" (1982), de Luisa Valenzuela, es una expresión compleja y alucinante de este tabú. El masoquismo de la víctima es la otra cara del sadismo del victimario.

Dentro del enfrentamiento entre el poder y el ciudadano, prevalece la tematización de la violencia desde arriba, lo que se explica por las numerosas dictaduras vividas durante el siglo XX. La misma razón explica que sea mucho menos frecuente la tematización de la violencia desde abajo, es decir, la de los movimientos revolucionarios, violencia que, por lo demás, se considera justificada por las circunstancias políticas. Volveré sobre esta problemática en la próxima parte de este ensayo.

Un problema particular lo constituyen los movimientos revolucionarios que llegaron al poder. Según una dialéctica magistralmente analizada por Sartre en Critique de la raison dialectique (1960), los movimientos revolucionarios de un cierto tipo se definen como libertarios en la fase de su lucha contra el poder, pero se convierten a su vez en opresivos una vez obtenido el mismo. Un pensamiento análogo asoma en un lugar de Libro de Manuel, de Julio Cortázar. ${ }^{27}$

La literatura de la Revolución Mexicana puede considerarse como ilustración de este pensamiento pesimista. Desde los comienzos, los autores tematizaron la violencia revolucionaria y su degradación en bandoleris-

26 Scipioni, Estela Patricia: Torturadores, apropiadores y asesinos. El terrorismo de estado en la obra dramática de Eduardo Pavlovsky. Kassel, 2000, pág. 258.

27 Me refiero a un pasaje en el cual el personaje de Andrés expresa su miedo hacia "los fascistas de la revolución”, revolucionarios que se convertirán en opresores una vez llegados al poder. Cotázar, Julio: Libro de Manuel. Buenos Aires, 1973, pág. 351. 
mo, como lo atestigua la novela Los de abajo (1915), de Mariano Azuela. Tampoco se callan las violentas luchas por el poder entre los revolucionarios victoriosos - cuya expresión más importante es, tal vez, La sombra del caudillo (1929), de Martín Luis Guzmán—, denuncia que continúa en publicaciones recientes, como, por ejemplo, las novelas de Ignacio Solares.

Muy distinto ha sido el caso de la Revolución Cubana, cuya dimensión violenta no ha sido retomada en la literatura de una manera análoga a la de la Revolución Mexicana. ${ }^{28}$ La causa de esta diferencia entre ambos corpus resalta mejor en algunos pasajes del libro de Rogelio Rodríguez Coronel sobre la novela de la Revolución Cubana. La novela de la Revolución Mexicana - escribe-

destila amargura, desesperanza o incomprensión a partir de ideales que en la práctica son mutilados; ideales que históricamente resultan anacrónicos y utópicos por estar referidos a una justicia social irrealizable en el contexto de la época $[\ldots] .^{29}$

El novelista de la Revolución Cubana, por el contrario, "colabora en la defensa de un mundo que pugna por establecer nuevos valores, por remodelar a la sociedad y al hombre". ${ }^{30}$ En otras palabras, la actitud del novelista de la Revolución Mexicana es utópica y negativa, mientras que la de la Revolución Cubana es realista y positiva. El carisma de Fidel Castro y, tal vez más aun, el mito del Che en tanto que encarnación del sueño del hombre nuevo en la nueva sociedad, sobrevivieron a los diversos escándalos (el de Padilla de 1971 y el de Ochoa en 1989, entre otros). Ni siquiera la extensa literatura del exilio ha conseguido imponer una imagen diferente, a pesar del éxito mundial de algunos de sus autores como Guillermo Cabrera Infante o Reinaldo Arenas. Es sólo recientemente cuando una postura anticastrista hasta favorece el éxito, como en el caso de Zoe Valdés, lo que puede considerarse como un indicio (entre otros) del cambio en la percepción literaria de Cuba, sobre todo en Europa.

Sin embargo, el análisis de la violencia política en la literatura sería incompleto, incluso superficial, si se limitara a la violencia misma. Por lo menos tan importante como ésta es su efecto en los hombres y la sociedad: el miedo, el terror interiorizados. La violencia transforma y deforma a los

28 Habría que discutir, tal vez, en este contexto, las novelas históricas de Alejo Carpentier y de Lisandro Otero, que trataré posteriormente en otro contexto.

29 Rodríguez Coronel, Rogelio: La novela de la Revolución Cubana (1959-1979). La Habana, 1986, pág. 31 .

30 Ibídem, pág. 285. 
hombres, tanto a los victimarios como a sus víctimas, sean éstos seres que realmente la sufren o que sólo la temen. En este sentido cabe hablar de un "hombre de la violencia", que aparece en circunstancias políticas concretas. Yo el Supremo, de Roa Bastos, o El otoño del patriarca, de García Márquez, son excelentes estudios de la deformación de la personalidad del dictador, como lo son, para citar la contrapartida del personaje, las novelas de las dictaduras militares en el Cono Sur en cuanto a la deformación que padecen las víctimas. A modo de ejemplo puede citarse Cuarteles de invierno, de Osvaldo Soriano, o algunos cuentos de Mempo Giardinelli y Luisa Valenzuela.

Parecería lógico esperar que, con la transición democrática en los países del Cono Sur y el Brasil, con el ocaso de los movimientos guerrilleros (con excepción de Colombia), el problema de la violencia política hubiera perdido peso y actualidad en el subcontinente latinoamericano. Y, en efecto, así es, en cuanto que la dialéctica de dictadura y resistencia como tema actual ha desaparecido de la literatura. Sin embargo, esta desaparición es compensada por su reaparición bajo otras formas. En primer lugar, aparece como reflexión sobre el pasado inmediato, lo que se puede observar en un gran número de obras de los últimos años, las cuales atestiguan que la violencia sigue siendo un trauma para los diferentes pueblos. Se podría llegar a comparar esas obras con un tratamiento psicológico colectivo, en el que la superación del trauma exige su previa conscientización.

En segundo lugar, el problema de la violencia política aparece en las llamadas nuevas novelas históricas, sobre todo las que se ubican en tiempos de la Conquista o de las Guerras de Emancipación. Tal vez sea la relativa desaparición de la violencia política la que deja la mirada libre para buscar las raíces de la violencia en el pasado lejano del subcontinente. Desde esta perspectiva, se explicaría que la novela histórica apareciera como fenómeno masivo en ciertos países justo en el período de la transición democrática.

En tercer y último lugar, queda el tema de la violencia en tiempos democráticos, tema más difícil en cuanto que no conlleva la oposición blanco y negro propia de los tiempos de la dictadura. El estado ya no es, $a$ priori, el enemigo, ni la resistencia armada puede estar, a priori, justificada. Sin embargo, ni las estructuras estatales ni las antiguas ideologías pueden haber cambiado de un día al otro. En el momento en que escribo estas líneas, leo una noticia en El País sobre el "Primer informe relativo al cumplimiento de la Convención contra la tortura y otros tratos o penas crueles, 
inhumanas o degradantes en el Brasil" ${ }^{31}$ Informes similares en otros países latinoamericanos llevarían, tal vez, a conclusiones análogas. Sea como fuere, la elaboración y publicación del informe constituye un paso significativo hacia la humanización del poder político.

Esta breve reflexión sobre la literatura latinoamericana del siglo XX nos ha mostrado la estrecha interrelación entre la violencia política y la representación literaria de la misma en sus distintas formas de expresión. Sin embargo, el análisis de la producción literaria respectiva se mantuvo en un nivel descriptivo. La expresión literaria de la violencia sólo adquiere su verdadera significación si incluimos en la discusión la reflexión de los autores sobre la misma. Esto es lo que me propongo hacer en la próxima y última parte de este ensayo.

\section{La reflexión sobre la violencia}

"Son pocas las discusiones sobre la violencia en la novela nuestra", escribe Dorfman, y menciona como excepción Mañana los guerreros (1964), de Fernando Alegría. ${ }^{32}$ Esta observación se limita obviamente a las discusiones explícitas que habrán de aparecer con más frecuencia en las obras posteriores. Sin embargo, me parece imprescindible incluir en el análisis las reflexiones implícitas, con lo cual se ensancha notablemente el campo de observación.

De modo general, en la reflexión sobre la violencia política podemos distinguir tres núcleos: (1) el (presunto) ser violento del mundo latinoamericano; (2) la violencia estatal; (3) la violencia de la resistencia. Empiezo con el primer núcleo. Vuelvo a la tesis de Dorfman citada al comienzo de la parte anterior, en la cual postula el ser violento del mundo hispanoamericano. En el desarrollo de su tesis, el crítico chileno mezcla argumentos históricos y sociales con argumentos filosóficos de índole existencialista y cartesiana. "La agresión ha comenzado hace mucho tiempo - escribe en su argumentación histórica-; América es el fruto de una violencia prolongada". ${ }^{33}$ Por otra parte, ve la causa de la violencia en el sistema social: "Nuestra violencia, por lo tanto, creada por un sistema social que fuerza al $90 \%$ de sus habi-

31 "Brasil reconoce que la democracia no ha acabado con la tortura", El País, 23 de agosto de 2000, pág. 6 .

32 Dorfman, A.: "La violencia en...", pág. 16.

33 Ibídem, pág. 12. 
tantes a no saber siquiera si vivirá más allá de mañana [...]" ${ }^{34}$ Los dos argumentos aparecen como un leitmotiv en la reflexión de los intelectuales sobre la violencia en América Latina. En este contexto son particularmente significativas dos obras de Eduardo Galeano: Las venas abiertas de América Latina (1970), y los tres tomos de Memoria del fuego (1986).

Sin embargo, Dorfman va más allá de esta argumentación históricosocial y pasa al nivel filosófico. El hombre hispanoamericano, dice, ha interiorizado la violencia hasta tal punto que ésta se confunde con su ser íntimo: "Soy violento, dice el personaje nuestro, lo siento dentro de mí, es mi personalidad; y al mismo tiempo fluye afuera, como labios de aire, uniéndome con los otros, separándome de ellos" ${ }^{35}$ Resulta imposible, para el hombre hispanoamericano, eludir la violencia: "Para parafrasear a Sartre, estamos condenados a la violencia; se ha convertido en el acto cotidiano, en la negra luz que nos alumbra". ${ }^{36}$ En última instancia, la violencia es el fundamento de la identidad personal, tal como lo revela la referencia (esta vez implícita) a Cartesio cuando escribe: "Mato, luego existo". ${ }^{37}$

La posición de Dorfman frente al mundo de la violencia analizado por él es ambigua: por un lado, forma parte integrante del mismo en tanto que hispanoamericano; por otro lado - y al mismo tiempo- en tanto que crítico, se coloca fuera de él. Posición doblemente ambigua, porque, al definir al hombre hispanoamericano como hombre de la violencia, parece caer en un cierto fatalismo; pero, por otra parte, al describir esta situación, la hace emerger al nivel de lo consciente y, al hacerlo, apela a los hispanoamericanos - y, por extensión, latinoamericanos- a cambiarla. El ensayo de Dorfman puede considerarse, en este último sentido, como un ejemplo de la literatura comprometida en el sentido sartreano.

Dentro del mismo campo de la reflexión filosófica y literaria se sitúa la obra de Ernesto Sabato que constituye en su conjunto, tal vez, el mejor ejemplo de la expresión literaria de la violencia y de la reflexión sobre ella. Su pensamiento profundamente moral se mueve en un campo entre filosofía y teología y se enriquece con la dimensión política en las novelas Sobre héroes y tumbas y Abaddón, tanto en su relación con el pasado (Rosas y Lavalle) como con el presente de entonces (Perón y las dictaduras militares). A pesar de la cercanía innegable al pensamiento de Dorfman, sus con-

34 Ibídem, pág. 17.
35 Ibídem, pág. 15.
36 Ibídem, pág. 16.
37 Ibídem, pág. 17. 
clusiones son opuestas. Para Sabato, el latinoamericano no es, por causas históricas y sociales, una variante humana particularmente violenta, sino que es violento en tanto que ser humano que entra en la oscura teología del mal. El pensamiento de Sabato es universal, sin que él niegue nunca sus raíces argentinas.

La teatrista argentina Griselda Gambaro trata la misma problemática desde una perspectiva psicológico-política. En una escena de su pieza Información para extranjeros ${ }^{38}$ la autora incluye un famoso experimento psicológico cuyo objetivo era medir la interrelación entre obediencia y violencia. El experimento estaba disfrazado de experimento pedagógico para determinar hasta qué punto el dolor físico (o el miedo a éste) podía acelerar el aprendizaje. Siguiendo las órdenes de un coordinador, el sujeto de experimentación (llamado maestro) debía castigar con choques eléctricos los fallos del "alumno" que se encontraba en otra sala, y de quien sólo escuchaba la voz recitando el texto que debía memorizar y sus gritos ante los choques eléctricos que supuestamente recibía al equivocarse. La fuerza de éstos iba de los 15 hasta los 450 voltios mortales. Cito la conclusión dirigida al público:

Coordinador
Esta experiencia, con los gritos grabados y las torturas simuladas, se repitió ciento
ochenta veces. Desgraciadamente, este primer maestro que continuó los castigos has-
ta los cuatrocientos cincuenta voltios que determina la muerte, no constituyó una
excepción. El ochenta y cinco por ciento de los maestros [alemanes] procedió en la
misma forma. El mismo test se realizó en 1960 en los Estados Unidos. ¿Los resulta-
dos?: sesenta y seis por ciento. Obedecían reglas y no eran responsables.
Guía
[...] Bueno, basta. [...] La experiencia se realizó en Alemania y Estados Unidos. Entre
nosotros sería completamente absurda. ${ }^{39}$

En esta escena, la autora invita irónicamente al espectador a comparar la disposición a la violencia de los argentinos con la de otras naciones. ${ }^{40}$

38 Incluida en Gambaro, Griselda: Teatro 2. Buenos Aires, 1987, págs. 67-128. La pieza lleva la fecha de 1973; hasta donde yo sé, no llegó a estrenarse nunca.

39 Ibídem, pág. 83s.

40 Gambaro se refiere en esta escena a los famosos experimentos realizados por Stanley Milgram en la Universidad de Yale, en los años 1960-1963. David M. Mantell repitió los experimentos, en 1970, en el Max-Planck-Institut de Munich. Los resultados obtenidos por Milgram valen para todos los países y culturas, según un artículo-reseña de Meeus, Wim y Quiten Ranikmakers: "Autoritätsgehorsam in Experimenten des Milgram-Typs. Eine Forschungsübersicht". En: Zeitschrift für Sozialpsychologie 20, 1989, págs. 70-85. 
Al mismo tiempo, tematiza la relación entre mando y obediencia que es central para el mantenimiento del poder. Y es en este punto donde la literatura va más allá de los análisis de las ciencias políticas, porque personaliza la problemática y entra en la psicología de los personajes. La violencia en tanto que instrumento del poder es tan eficiente porque causa placer a los que la ejercen. En otras palabras, la violencia política se funda también en la disposición sádica de los hombres, en el placer cruel de torturar al otro. Señalé más arriba la oscura dicotomía entre sadismo y masoquismo. Ahora bien, tal como la violencia puede quebrar la personalidad de un individuo, lo puede también hacer con la personalidad colectiva de un pueblo. Así aparece en una reflexión de la protagonista de la última novela de Vargas Llosa, que trata de la dictadura de Trujillo en Santo Domingo:

[...] a fuerza de leer, escuchar, cotejar y pensar, has llegado a comprender que tantos millones de personas, machacadas por la propaganda, por la falta de información, embrutecidas por el adoctrinamiento, el aislamiento, despojadas de libre albedrío, de voluntad y hasta de curiosidad por el miedo y la práctica del servilismo y la obsecuencia, llegaran a divinizar a Trujillo. No sólo a temerlo, sino a quererlo, como llegan a querer los hijos a los padres autoritarios, a convencerse de que azotes y castigos son por su bien. ${ }^{41}$

Peor es el caso de los hombres que se han puesto al servicio del dictador y a quienes "Trujillo les sacó del fondo del alma una vocación masoquista, de seres que necesitaban ser escupidos, maltratados, que sintiéndose abyectos se realizaban". ${ }^{42}$ Estos hombres son víctimas y victimarios a la vez y su masoquismo en relación con el dictador se convierte en sadismo en relación con el pueblo.

Es comprensible que la oscura dicotomía entre sadismo y masoquismo constituya un tabú porque puede llevar a concluir, como dice el famoso refrán, que "no el asesino, sino el asesinado es el culpable". Sin embargo, me parece meritorio el hecho de que algunos autores hayan osado tocar este tabú porque, según uno de los a prioris del psicoanálisis, la cura sólo es posible si el síndrome que causa la enfermedad es llevado del inconsciente a la luz de la conciencia.

Ante la tesis de Dorfman y de quienes la abrazan, que supone que el ser latinoamericano es particularmente violento, surgen otras voces - tal el caso de Griselda Gambaro en la escena analizada- que la niegan explí-

41 Vargas Llosa, Mario: La Fiesta del Chivo. Madrid, 2000, pág. 75.

42 Ibídem, pág. 76. 
cita o implícitamente o, por lo menos, la ponen en duda. La negativa explícita se encuentra en algunas obras en las cuales se denuncia la primera postura como expresión de una falsa superioridad moral, sobre todo por parte de los europeos. En este sentido se debe entender la reflexión del protagonista de Qué solos se quedan los muertos, citado como epígrafe de este ensayo, al enumerar las barbaridades cometidas en Europa durante el siglo XX. Del mismo modo, en una escena en la que García Márquez enfrenta, en El general en su laberinto (1989), a Bolívar y a un francés imbuido del sentimiento de superioridad europea en una discusión sobre política y violencia, el Libertador justifica las violencias ordenadas por él en las guerras de emancipación, y recuerda a su interlocutor las barbaridades que los europeos cometieron a lo largo de su historia. De modo terminante, niega a éstos la autoridad moral de reprocharle esas violencias, agregando que "si una historia está anegada de sangre, de indignidades, de injusticias, ésa es la historia de Europa". ${ }^{43}$ A pesar de que esta argumentación está ligada, en la novela, al personaje de Bolívar, podemos sacarla de su contexto y utilizarla en el nuestro. La argumentación tiene dos objetivos: (1) negar a los europeos el derecho moral de juzgar a los latinoamericanos; y (2) considerar la problemática dentro de una evolución histórica. Es el segundo punto el que me interesa aquí. En la argumentación de la novela marqueciana, la violencia latinoamericana aparece como resultado de ciertas circunstancias históricas y sujeta a cambios históricos. En este sentido, se opone a la tesis de Dorfman sobre el carácter existencial de la violencia del latinoamericano.

La reflexión de los autores, tanto sobre la violencia desde arriba como sobre la violencia desde abajo, está más cerca de la realidad política. El primer caso se da casi exclusivamente en novelas o dramas históricos, mientras que el segundo se da preferentemente en obras cuyo tiempo narrativo es cercano al presente de la escritura, en ambos casos, sin embargo, con notables excepciones. En cuanto a la frecuencia de la representación de la violencia y de la reflexión sobre ella por parte de los autores, podemos observar una relación inversa: es mucho más frecuente la representación (y denuncia) de la violencia desde arriba que la de la violencia desde abajo, mientras que en la reflexión es esta última la que aparece en primer plano. Las causas son obvias, puesto que la violencia ejercida por parte del poder es casi unánimamente considerada a priori como negativa (cf. arriba

43 García Márquez, Gabriel: El general en su laberinto. México, 1989, pág. 131s. 
la argumentación de Schwartländer) y no exige, por ende, una reflexión sobre su justificación eventual, mientras que en el caso de la violencia desde abajo, sí la exige. ${ }^{44}$

Empiezo, pues, con esta última, sirviéndome de tres obras significativas de los años '70 y '80: Libro de Manuel (1973), de Julio Cortázar, Zero (1975), de Ignacio de Loyola Brandão, y Qué solos se quedan los muertos (1985), de Mempo Giardinelli.

En Libro de Manuel, Cortázar relata la historia de un grupo de jóvenes latinoamericanos, residentes en París, que preparan el secuestro de un personaje importante para conseguir, de este modo, la libertad de ciertos presos políticos en América Latina. La argumentación de la que se sirve Cortázar para justificar su actuación es doble, implícita y explícita. En el nivel implícito, el autor opone la violencia de los regímenes dictatoriales en América Latina a la acción del grupo. Aquéllos son evocados por medio de recortes periodísticos, que son integrados directamente en el texto. En cuanto a la acción del grupo, el aspecto violento de la misma es cuidadosamente minimizado, hasta el nombre que le dan (la gran joda) le confiere un aspecto lúdico.

En la argumentación explícita, cabe señalar un pasaje en el cual un personaje cita la carta de la esposa de un periodista, que había sido torturado y asesinado, y en la que ésta opone dos tipos de violencia:

Es importante darse cuenta de que la violencia-hambre, la violencia-miseria, la violencia-opresión, la violencia-subdesarrollo, la violencia-tortura, conducen a la violencia-secuestro, a la violencia-terrorismo, a la violencia-guerrilla; y que es muy importante comprender quién pone en práctica la violencia: si son los que provocan la miseria o los que luchan contra ella. ${ }^{45}$

La argumentación es en extremo clara. El origen de la violencia se encuentra en la situación política (opresión por parte de los regímenes dictatoriales) y la social (miseria, hambre, subdesarrollo). La violencia desde abajo (secuestro, terrorismo, guerrilla) es una consecuencia directa de aquélla y es, por ende, justificada, mientras que aquélla es injustificable. En el prólogo, Cortázar se refiere a la lucha "en pro del socialismo latinoamericano", y en una posdata del 7 de septiembre de 1972 señala los hechos

44 Para una discusión profundizada de la justificación de la violencia desde abajo, sería imprescindible recurrir al libro de Georges Sorel Réflexions sur la violence (París, 1908), redescubierto por algunos politólogos en los años que siguieron al 68.

45 Cortázar: Libro de Manuel..., pág. 323. 
sangrientos de Trelew, ocurridos poco antes, confrontándolos con las proclamas de paz en vísperas de los juegos olímpicos de Munich. ${ }^{46}$

En Zero, por el contrario, la argumentación es sólo implícita. Loyola Brandão pone cara a cara las proclamas de una moral hipócrita, ampulosa y altisonante de la dictadura y su actuación represiva con la violencia de los guerrilleros, que de este modo aparece como necesaria y justificada. Hasta aquí, la argumentación implícita se parece a la de Libro de Manuel. Empero, el autor brasileño va mucho más allá de esta oposición relativamente simple al enfrentar la acción colectiva y guerrillera con la criminal e individual, con la vida caótica de la gran urbe y la violencia sexual. Zero es una de las novelas latinoamericanas más violentas del siglo pasado, título que comparte, tal vez, con La Virgen de los Sicarios, de Fernando Vallejo. En ella aparecen, en estrecha interrelación, la violencia de un régimen dictatorial, la contraviolencia de la guerrilla, la criminalidad, el sadismo sexual de los hombres y el sufrimiento de las mujeres, si bien no falta la expresión de un cierto placer masoquista por parte de ellas.

En ambas novelas, la lucha revolucionaria está ligada a un ideal, el del hombre nuevo en la nueva sociedad, que aparece como un leitmotiv utópico en la literatura de esos años y que está encarnado en la figura del Ché convertida en un mito calcado sobre la de Cristo. En el fondo de la reflexión, se halla el viejo problema del fin y de los medios, es decir, el problema de si el ideal justifica la violencia de los medios utilizados para alcanzarlo y hasta qué punto.

La problemática es presentada de modo diferente en Qué solos se quedan los muertos, de Mempo Giardinelli. Esta novela de corte policial narra la historia de un ex-guerrillero argentino exiliado en México, cuya compañera de los años de guerrilla - ahora convertida en la amante de un narcotraficante en Zacatecas - pide su ayuda. En capítulos alternados, aparecen la narración policial y las reflexiones del protagonista sobre su pasado. En un punto dado, el protagonista reflexiona sobre los orígenes de la violencia en su país. En su reflexión no apela ni a la Conquista ni a la situación social como respuesta, sino a una educación "en la violencia de ser juzgados en lugar de comprendidos", una educación autoritaria que convirtió, a su generación, desde chicos en "pequeños centuriones, militarcitos sometidos mediante el grito y el castigo", una educación, pues, que tuvo como resultado que su generación interiorizara la violencia. ${ }^{47}$

46 Ibídem, pág. 8s.

47 Giardinelli, Mempo: Qué solos se quedan los muertos. Buenos Aires, 1985, págs. 179-181. 
Como en El general en su laberinto, se trata de una reflexión puesta en boca de un personaje novelesco. Empero, otra vez, esta reflexión rebasa las fronteras del discurso personal, de modo que me parece lícito relacionar este pasaje con el autor, quien cuestiona, tal vez por primera vez en la literatura latinoamericana, la justificación de la contraviolencia. Es cierto que Giardinelli rechaza todo "empate histórico" entre los "golpistas, torturadores, retóricos, los concupiscientes y los mercaderes" y su generación, aun a pesar de reconocer sus "errores, intolerancia y autoritarismos, los afiebrados delirios de muchos". Sin embargo, al cuestionar la actuación de su propia generación - que se rebeló contra la autoridad del estado dictatorial- marca un paso decisivo en la discusión sobre la justificación de la violencia desde abajo.

Aparte de esta problemática, el pasaje analizado contiene otro aspecto importante. Al buscar las causas de la violencia de los jóvenes revolucionarios en la formación autoritaria que sufrieron, el personaje novelesco (y, con él, implícitamente el autor) relaciona la violencia que yace latente con la violencia política. Habría, pues, como una predisposición de la sociedad hacia ella.

Mencioné anteriormente que el problema de la justificación de la violencia revolucionaria aparece también en algunas novelas históricas. Como ejemplo cabe señalar dos novelas cubanas, muy diferentes en todos los sentidos, pero semejantes en cuanto al problema que aquí nos ocupa. Se trata de El siglo de las luces (1962) de Alejo Carpentier, y de Temporada de Angeles (1983) de Lisandro Otero, que evocan dos grandes revoluciones de la historia europea: la francesa de 1789 y la inglesa de Oliver Cromwell en el siglo XVII. Ambas novelas tematizan la violencia revolucionaria, justificada al comienzo pero que pierde su justificación al acceder los revolucionarios al poder. El tema de la degeneración de la violencia revolucionaria acerca estas novelas a las de la Revolución Mexicana. Ambas guardan una relación muy ambigua con respecto a la Revolución Cubana, y tal vez me lleven a matizar la opinión que emitiera anteriormente en cuanto a la representación literaria de la violencia de esta revolución.

De la discusión sobre estas dos novelas a la reflexión sobre la violencia estatal, que se encuentra - como señalara anteriormente- casi exclusivamente en la novela histórica sólo hay un paso. En este contexto, son dos las épocas de mayor relevancia: la Conquista y las Guerras de Emancipación.

En las obras que toman la Conquista como tema central prevalece, de modo general, la denuncia de la violencia de los conquistadores. A veces 
se sirven de la figura de Bartolomé de las Casas para expresar las denuncias, a veces de la de Lope de Aguirre, cuya imagen ha cambiado de traidor a precursor de la Emancipación. En cuanto al dominico, tal vez no se valora adecuadamente el hecho de que no fue una figura solitaria, sino, por el contrario, la punta más avanzada de un grupo de teólogos, juristas y conquistadores españoles que cuestionaron el derecho de conquista y denunciaron sus excesos desde la perspectiva de los vencedores. Sería interesante comparar a este respecto las novelas latinoamericanas con las españolas sobre la temática.

Muy distinta se presenta la problemática en las obras sobre las Guerras de Emancipación y los comienzos de las repúblicas modernas. No cabe duda de que las repúblicas hispanoamericanas modernas deben su existencia a una rebelión armada y (es ocioso decirlo) violenta. En la literatura, esta violencia es asumida (y generalmente justificada) y no ocultada, como ocurre en la novela de Jorge Amado Tocaia Grande. A face oscura (1984), en la cual una ciudad próspera que celebra sus cien años de existencia, oculta sus comienzos violentos. Un ejemplo temprano de la evocación de la violencia de las guerras de emancipación es la novela Las lanzas coloradas (1931), de Arturo Uslar Pietri. Ya discutí anteriormente la defensa que, en El general en su laberinto, hace el personaje de Bolívar de las medidas violentas que impone.

Más difícil de evaluar es la autodefensa del Dr. Francia, primer dictador de la historia latinoamericana, en Yo el Supremo (1975), de Augusto Roa Bastos. El problema reside en la doble dimensión de la novela que, en el momento de su publicación, fue leída como novela dictatorial, mientras que ahora, desde una distancia temporal de 25 años, es leída más bien como histórica. La lectura de la novela en tanto que dictatorial o histórica influye de modo decisivo en la evaluación de la violencia del régimen del Dr. Francia. En tanto que novela dictatorial, el protagonista será percibido como un precursor del general Stroessner, dictador del Paraguay de entonces. La autojustificación por parte del Dr. Francia aparecerá, en esa lectura, como mera coartada. En la lectura histórica, por el contrario, el caso se presenta de modo diferente. El personaje del Dr. Francia parangona sus actos violentos con su éxito político: haber construido el primer país independiente en territorio sudamericano, y haber mantenido la paz interior y exterior durante décadas, mientras que los países vecinos se hundían en guerras civiles. En el razonamiento del Dr. Francia, la violencia ejercida por él es mínima en relación con los efectos benéficos de la misma, y es 
justificada, en última instancia, por la llamada razón de estado. No cabe duda de que la figura del dictador reconoce al final de su vida su fracaso, lo que influirá necesariamente en la evaluación de su autodefensa que, a pesar de todo, queda abierta a interpretaciones contradictorias.

Como señalé anteriormente, la reflexión sobre la violencia estatal también se encuentra, si bien con mucho menos frecuencia, en obras situadas en el presente. Me refiero a Noticia de un secuestro (1996), de Gabriel García Márquez, y El Décimo Infierno (1999), de Mempo Giardinelli. Ambas obras tienen en común, además, el relacionar la violencia con la democracia, si bien bajo perspectivas opuestas.

La obra marqueciana, mezcla de reportaje y ficción, es difícilmente clasificable en cuanto a su género. El juego de palabras inglés de fact y fiction que ha llevado, si no me equivoco, a la nueva denominación de faction, es la expresión que mejor expresa su género.

García Márquez narra en su obra el secuestro —en los años 1990 y 1991 - de unas personas prominentes por parte de los narcotraficantes, hechos que constituyeron episodios salientes en la llamada guerra sucia entre el narcotráfico y el estado. En algunos comentarios intercalados, el autor reflexiona sobre la violencia en una democracia, comentarios que forman en su conjunto una teoría política. Esta reflexión marqueciana se centra en dos puntos. El primero - en la estructura de la obra el más importantees la estrategia seguida por el presidente César Gaviria de convertir la guerra por parte del estado en un proceso judicial, intentando "crear una alternativa jurídica contra el terrorismo", "una estrategia que no fuera de guerra ni de paz sino de justicia". ${ }^{48}$ En términos de este ensayo, esta estrategia consiste en reemplazar la violencia tal cual por la coerción justificada legalmente.

Empero, ¿puede sostenerse esta estrategia en tiempos de una violencia máxima? Es este el segundo punto de la reflexión propuesta en la obra. García Márquez evoca la situación de Medellín en esos años, "una ciudad martirizada por la violencia":

En los primeros dos meses del año de 1991 se habían cometido mil doscientos asesinatos - veinte diarios - y una masacre cada cuatro días. Un acuerdo de casi todos los grupos armados había decidido la escalada más feroz de terrorismo guerrillero en la historia del país, y Medellín fue el centro de la acción urbana. Cuatrocientos cincuenta y siete policías habían sido asesinados en pocos meses. ${ }^{49}$

48 García Márquez: Noticia..., págs. 81 y 84.

49 Ibídem, pág. 203. "Medellín la capital del odio", dice el narrador de La Virgen de los Sicarios (pág. 10). Cf. Walde, Erna von der: "La novela de sicarios y la violencia en Colombia", en Iberoamericana. Nueva época 1, n. ${ }^{\circ}$ 3, 2001, págs. 27-40. 
Un detalle importante en esta cita es la referencia al "terrorismo guerrillero": el estado se ve, pues, amenazado tanto por el terrorismo de los narcotraficantes como por el de las guerrillas.

Ahora bien, el antecesor de César Gaviria en el cargo de presidente de la república, Virgilio Barco, había creado en 1989 un Cuerpo Elite para combatir el terrorismo. De este cuerpo se desprendió más tarde "un grupo especializado en operaciones urbanas" que se estableció en Medellín. ${ }^{50}$ El punto decisivo es el hecho de que García Márquez alude a las medidas obviamente violentas de este Cuerpo Elite sólo veladamente, lo que resalta más si lo comparamos con la denuncia explícita que hace de la violencia por parte de los narcos y los guerrilleros. El pasaje puede leerse como una aceptación tácita de la estrategia estatal. Una vez más, como fuera el caso - ya discutido - de Roa Bastos, nos encontramos con un autor que se enfrenta al problema de la razón de estado.

Si profundizamos en esta problemática, llegamos a la cuestión del estado de emergencia, uno de los problemas más intrincados tanto para la teoría como para la práctica políticas. La situación de Medellín, tal como la describe García Márquez, es sin duda alguna de emergencia. ¿Están justificadas, por ende, las acciones del Cuerpo Elite? Desafortunadamente, la reflexión de García Márquez termina ahí, sin llegar a discutir los límites del poder estatal y las licencias que pueden tomarse en un estado de emergencia. En los hechos narrados, el problema se soluciona de una manera factual, en tanto que la "alternativa jurídica contra el terrorismo" seguida por el presidente Gaviria es exitosa.

Esta ausencia de una reflexión sobre el estado de emergencia en una democracia, ausencia común a las obras discutidas en este ensayo, se explica, tal vez, por el hecho de que las dictaduras militares solían justificar el golpe de estado precisamente con este argumento. El abuso de la utilización del estado de emergencia ocultó el hecho de que la democracia necesita reglamentos constitucionales precisos para que no degenere en dictadura.

Mientras que la reflexión de García Márquez atestigua, a pesar de todo, una confianza en la democracia, la obra de Mempo Giardinelli está impregnada de una profunda desconfianza, incluso desprecio, hacia el sistema concreto que ha salido del proceso de la transición democrática argentina. La novela El décimo infierno narra la historia de un adulterio, en la cual los amantes deciden asesinar al esposo de la mujer (y mejor amigo del

50 Ibídem, pág. 204. 
amante), sin causa aparente, ya que el triángulo funciona perfectamente. $\mathrm{El}$ asesinato del marido arrastra a los amantes en una verdadera tormenta de violencia, en la cual un asesinato lleva a otro hasta acabar en el asesinato mutuo. La violencia se convierte en el décimo círculo del infierno de Dante. Ahora bien, esta historia, que parece ser exclusivamente privada, tiene una dimensión política, lo que se hace patente en una reflexión del protagonista en la cual éste rechaza toda condena en un país "en el que después de los milicos, que fueron unos cerdos y unos ineptos, ahora gobiernan los mafiosos, los ladrones y los hijos de puta". ${ }^{51}$

Esta reflexión del protagonista (y con ella, de la novela) es difícil de interpretar. Se puede ver como una simple coartada por parte del personaje que busca una justificación fácil a su violencia. Su autodefensa afiebrada tiene, sin embargo, un fondo serio, en tanto que expresa una profunda desconfianza en la nueva democracia, democracia que aparece como un juguete en manos de una nueva élite política corrupta y mafiosa. En este sentido, la novela se puede leer como una crítica implícita al gobierno de Menem. Si esta interpretación es correcta, podemos relacionarla con la reflexión del protagonista de Qué solos se quedan los muertos, discutida más arriba. Si en esta novela la violencia política se basó en la violencia privada latente, en aquélla, la violencia privada se expande en un clima político impregnado de violencia. Ambas formas de violencia se condicionan mutuamente.

Elegí las dos obras, una de García Márquez y otra de Giardinelli, porque reflejan importantes aspectos del problema de la violencia en las democracias latinoamericanas, sin que pueda pretender haber presentado una discusión exhaustiva de la problemática.

\section{A manera de conclusión}

Al final de esta somera reflexión sobre la violencia en la literatura latinoamericana del siglo pasado, deseo volver a la pregunta por el interés político y literario de la representación de la violencia en la literatura. Estoy convencido de que sigue siendo válida la teoría de Sartre según la cual una

51 Giardinelli, Mempo: El Décimo Infierno. México, 1999, pág. 63. Argentina no se encuentra sola a este respecto. Cf. la reflexión del narrador de La Virgen de los Sicarios: "La ley de Colombia es la impunidad y nuestro primer delincuente impune es el presidente, que a estas horas debe de andar parrandiándose el país y el puesto" (pág. 20). 
de las funciones de la literatura consiste en la conscientización del lector o, en otras palabras, en el testimonio de la realidad, para impedir que nadie pueda disculparse aduciendo ignorancia, declarándose inocente. Escribí adrede "una de las funciones", con lo que me distancio parcialmente de su teoría, porque al pretender que sea su función única, lo que era y es una tarea noble - ofrecer testimonio- se convierte en dictado inaceptable.

Mirando hacia atrás, desde la distancia temporal, resulta claro que los autores del siglo XX - y de manera particular los de su segunda mitadnunca olvidaron la realidad, incluso cuando utilizan formas que parecen apartarse de ella. Empero, al mismo tiempo, no quisieron aceptar imposición alguna desde afuera, lo que hubiera significado aceptar un dictado que se puede considerar, en última instancia, como una forma espiritual de la violencia. Con la libertad de expresión defendieron también la libertad cívica en general. La reflexión sobre la violencia en la literatura nos lleva, en última instancia, a una reflexión sobre la función de la literatura.

En la actualidad, la representación literaria de la violencia y la reflexión sobre ella han entrado en una crisis profunda debido a dos problemas independientes uno del otro.

El primero se sitúa entre la realidad y las artes y se puede caracterizar de la siguiente manera. Por un lado, la percepción de la violencia por parte de la sociedad occidental se ha agudizado enormemente. Como ya lo mencionara, se considera hoy como violento lo que en otros tiempos no lo hubiera sido. Las ligas para la defensa de los derechos humanos - entre ellas, Amnistía Internacional- velan por el respeto de estos derechos en todo el mundo y denuncian su violación en los distintos países. Por otra parte, la literatura y, más aún, el cine, la televisión, los videoclips, recurren a la violencia de un modo que hubiera sido inconcebible hace sólo unas décadas y que va mucho más allá de la presencia de la violencia en la literatura en general que mencioné en la segunda parte de este trabajo. En nuestra cultura globalizada, la violencia es omnipresente hasta tal punto que se habla de un verdadero culto a la misma. Con la multiplicación de la violencia literaria crece la exigencia de innovar, lo que lleva a formas cada vez más rebuscadas, hecho que sin embargo no hace desaparecer sus manifestaciones más crudas. El éxito comercial de todas esas producciones se debe al hecho de que la percepción estética de la violencia es fuente de placer en el espectador, un hecho que ya reconocieron los filósofos de la Antigüedad y que ha sido desde entonces el escándalo de los moralistas. La violencia real se confunde con la violencia representada. Cabría preguntar- 
se si los autores latinoamericanos, al enfocar y denunciar en sus obras la violencia real (sea política o privada) han contribuido a la inflación de la violencia literaria, no importando en este contexto que lo hicieran con las más nobles intenciones. Tenemos y podemos confiar en la fuerza de su imaginación para que puedan salir de este círculo vicioso.

El otro problema es de orden político. Para su explicación, recurro otra vez al tratado de Solfsky citado más arriba. Este autor ve en la protección mutua contra la violencia una de las raíces de la sociedad humana. Sin embargo, dicha protección tiene un precio. En palabras de Solfsky: "La sociedad es un instrumento para la protección mutua. Ella termina el estado de la libertad absoluta. De aquí en adelante, ya no se permite todo". ${ }^{52} \mathrm{El}$ precio de la protección contra la violencia es una limitación de la libertad e implica un disciplinamiento social del individuo. Los intelectuales y escritores latinoamericanos de la segunda mitad del siglo XX, empujados, por una parte, por un ímpetu revolucionario y libertario, y horrorizados, por otra, por la opresión y violencia dictatoriales, optaron comprensiblemente por la libertad. Sin embargo, lo que era comprensible y, más aún, inevitable y necesario en tiempos de dictadura, se vuelve peligroso en tiempos de la democracia, si bien hay que reconocer que siguen existiendo sistemas políticos difícilmente clasificables. La ausencia de una teorización adecuada sobre la dicotomía entre libertad y disciplinamiento se nota en una tendencia entre los intelectuales latinoamericanos a denunciar el disciplinamiento social per se como negativo y dañino. ${ }^{53}$ Visto desde esta perspectiva, el problema de la violencia (otra vez, tanto la política como la privada) forma parte de un problema fundamental que consiste en la dicotomía, inherente a la sociedad humana, entre la libertad cívica y el inevitable disciplinamiento social. Buscar una solución teórica y práctica a esta dicotomía es una tarea para los intelectuales y escritores, y no sólo en América Latina. Como en el primer problema señalado, tenemos y podemos confiar en la fuerza de su imaginación.

52 Solfsky: Traktat über..., pág.10.

53 La problemática reaparece en los muchos artículos que siguieron a los acontecimientos del 11 de septiembre. Cito a modo de ejemplo el ensayo de Ignacio Sotelo en el que discute sobre libertad/seguridad, "El binomio libertad-seguridad". El País, 9 de noviembre de 2001, pág. 23. Podemos suponer que estos acontecimientos llevarán a una revisión fundamental de la problemática aquí discutida. 